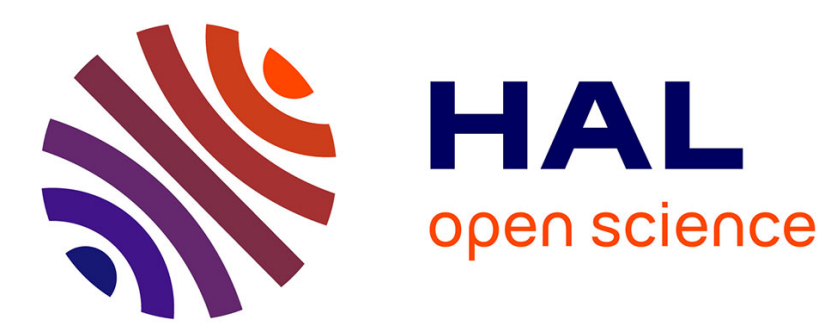

\title{
Climate Policy Must Favour Mitigation Over Adaptation Ingmar Schumacher
}

\section{To cite this version:}

Ingmar Schumacher. Climate Policy Must Favour Mitigation Over Adaptation. 2016. hal-01279017

\section{HAL Id: hal-01279017 \\ https://hal.science/hal-01279017}

Preprint submitted on 25 Feb 2016

HAL is a multi-disciplinary open access archive for the deposit and dissemination of scientific research documents, whether they are published or not. The documents may come from teaching and research institutions in France or abroad, or from public or private research centers.
L'archive ouverte pluridisciplinaire HAL, est destinée au dépôt et à la diffusion de documents scientifiques de niveau recherche, publiés ou non, émanant des établissements d'enseignement et de recherche français ou étrangers, des laboratoires publics ou privés. 


\section{ECOLE POLYTECHNIQUE}

\section{Climate Policy Must Favour Mitigation Over Adaptation}

Ingmar SCHUMACHER

February 15, 2016

Cahier $n^{\circ} \quad 2016-01$

\section{DEPARTEMENT D'ECONOMIE}

Route de Saclay

91128 PALAISEAU CEDEX

(33) 169333033

http://www.economie.polytechnique.edu/

mariame.seydi@polytechnique.edu 


\title{
Climate Policy Must Favour Mitigation Over Adaptation
}

\author{
Ingmar Schumacher*
}

February 15, 2016

\begin{abstract}
In climate change policy, adaptation tends to be viewed as being as important as mitigation. In this article we present a simple yet general argument for which mitigation must be preferred to adaptation. The argument rests on the observation that mitigation is a public good while adaptation is a private one. This implies that the more one disaggregates the units in a social welfare function, i.e. the more one teases out the public good nature of mitigation, the lower is average income and thus less money (per region, country or individual) is available for adaptation and mitigation. We show that, while this reduces incentives to invest in the private good adaptation, it increases incentives to invest in the public good mitigation since even small contributions of everyone can have significant impacts at the large. Conclusively, private adaptation thus must be viewed as a significant loss to global welfare. When taking this result to the data we find that a representative policy maker who relies on world-aggregated data would invest in both adaptation and mitigation, just as the previous literature recommends. However, a representative policy maker who relies on countrylevel data, or data at further levels of disaggregation, would optimally only invest in mitigation.

Keywords: climate change, mitigation, adaptation.

JEL classification: Q58, Q54.
\end{abstract}

*IPAG Business School, 184 boulevard Saint-Germain, 75006 Paris, France, and Department of Economics, Ecole Polytechnique Paris, France. Tel.: +352 621264575. E-mail: ingmar.schumacher@ipag.fr.

For comments I thank Partha Dasgupta, Rick van der Ploeg, Cees Withagen and Amos Zemel. 


\section{Introduction}

Adaptation is increasingly seen as an important contributor to climate policy, if not one of the main potential 'solutions' to our climate change problem (IPCC, 2014b). For example, the IPCC (Parry, 2007) notes that "[e]ffective climate policy aimed at reducing the risks of climate change to natural and human systems involves a portfolio of diverse adaptation and mitigation actions (very high confidence)." One, nevertheless, cannot but feel uneasy about this additional policy option as adaptation is likely to lead to more emissions simply because it reduces the damages we will face from climate change. As a result, this will give rise to a violation of many of the well-accepted definitions of sustainable development that were developed during the past years, especially strong sustainability (Neumayer, 2003) and approaches relying on capabilities (Sen, 1987). In the light of this the question raised in this article is as follows: If our climate policy were to be motivated by the first best, should adaptation be part of the policy mix or not? Or, slightly differently, assume a politician who attends the next Conference of Parties meeting comes to you and asks: Having the choice between mitigation and adaptation, how should I lobby all of the world's leaders to split up their money between the two?

One of the reasons for which adaptation has seen increasing attention on the policy agenda is that prominent research suggests that both adaptation and mitigation should play a role in climate policy. 
This result comes out of a growing literature that studies optimal climate policies in a representative agent framework. The articles that we are aware of and that have treated this question in an analytical approach, in order of publication year, are Kane and Shogren (2000), Lecocq and Shalizi (2007), Yohe and Strzepek (2007), De Zeeuw and Zemel (2012), Bosello et al. (2013), Bréchet et al. (2013), Ingham et al. (2013), Tsur and Withagen (2013), van der Ploeg and de Zeeuw (2013), and Zemel (2015). ${ }^{1}$ In this line of literature the discussion tends to circulate around the conditions under which adaptation and mitigation are substitutes or complements, and the optimal mix between adaptation and mitigation. The integrated assessment literature (Hope, 2006; De Bruin et al., 2009; Bosello et al., 2010) has verified these theoretical models empirically and came to the conclusion that adaptation should play a major role in climate policy. While this literature has elicited certain conditions under which, for example, adaptation (or mitigation alike) is optimally neglected (i.e. set to zero) in climate policy, this result tends to stem from either specific functional forms, or depends on the level of economic development of a country.

In addition to these studies, there are authors who suggest that mitigation should be viewed as a public good while adaptation is a private one. This literature tends to split the world into several regions and looks more deeply at the inefficiencies that are introduced by this

\footnotetext{
${ }^{1} \mathrm{~A}$ review and deeper discussion of these models is available in Agrawala et al. (2011), Bosello et al. (2010), Patt et al. (2010) and Konrad and Thum (2013).
} 
distinction. For example, Mendelsohn (2000) showed that private adaptation would be inefficiently low if joint adaptation would be possible (e.g. in the case of dam construction). A similar result has been shown in Ingham et al. (2013) and Buob and Stephan (2011), who find that adaptation is higher while mitigation is lower in a non-cooperative game compared to a cooperative one. Ebert and Welsch (2012) and Brechet et al. (2014) also study the differences between non-cooperative and cooperative results. Farnham and Kennedy (2014) show that reducing mitigation while increasing adaptation imposes a negative externality on other countries and thus adaptation can be welfare-reducing.

In this article we follow the second strand of literature by splitting the world more realistically into many regions or players and assume that mitigation is a public good while adaptation is a private one. Though this distinction has been made in articles that assess climate policy strategies, we will not focus on inefficiencies or particular game structures. Instead, in Section 2 we show that it is the public good character of mitigation that, for a sufficiently disaggregated welfare function, fully favours mitigation over adaptation. The intuition for this is that the more disaggregated the social welfare function the lower will be average income, and consequently at higher levels of disaggregation there will be less money available for private adaptation. In contrast, the potential sum for the public good mitigation can be very large with increasing levels of disaggregation, since small contributions of everyone can have significant impacts through the public good character that 
mitigation has. Intuitively, this should favour the provision of the public good mitigation over the private good adaptation. Hence, private adaptation represents a significant loss to global welfare. In Section 3, based on a numerical exercise calibrated to world data, we show that a policy maker who relies on a welfare function that is disaggregated at least at the country-level would optimally set adaptation equal to zero, while mitigation should be positive. Instead, a policy maker who evaluates welfare at a higher level of aggregation would invest in both adaptation and mitigation. We then argue in Section 3.1 as to what is the 'right' level of disaggregation when evaluating climate policies. Section 4 concludes with further lessons.

\section{A simple model}

We present a simple yet sufficiently general model to answer the question above. Assume there are $n=1, \ldots, N$ symmetric agents. They obtain average wages $W / N$, which they may spend on abatement or mitigation. Wages net of abatement and mitigation are reduced by multiplicative damages which are a decreasing function of the mitigation effort $M_{i} \geq 0$ and adaptation effort $A_{i} \geq 0$, implying that net

income is given by $Y_{i}=\left(1-D\left(\sum_{1}^{N} M_{i}, A_{i}\right)\right)\left(W / N-A_{i}-M_{i}\right)$. Mitigation has a public good character (via e.g. emission reductions that affect $\mathrm{CO}_{2}$ ), while adaptation is a private good (e.g. reinforcing one's home against storm damages). The agents have a concave utility func- 
tion that depends on the net income, with $U\left(Y_{i}\right)$, where the sum of mitigation and adaptation efforts are constrained by net wages. We impose the following set of very general assumptions.

Assumption 1 The utility function $U: \mathcal{R}_{+} \rightarrow \mathcal{R}$ is an increasing, concave transformation of $Y$.

Assumption 2 The damage function takes the form $D\left(\sum_{1}^{N} M_{i}, A_{i}\right) \in$ $(0,1), D_{M}^{\prime}<0, D_{M M}^{\prime \prime}>0, D_{A}^{\prime}<0, D_{A A}^{\prime \prime}>0$, and $\lim _{M \rightarrow \infty} D_{M}^{\prime}=0$, $\lim _{A \rightarrow \infty} D_{A}^{\prime}=0, D_{A M}^{\prime \prime}>0$, in addition to $\lim _{M \rightarrow 0} D_{M}^{\prime} \geq-\infty$ and $\lim _{A \rightarrow 0} D_{A}^{\prime}>-\infty$

While the first conditions in Assumption 2 on the shape of the damage function are natural, the last two limit conditions need some elaboration. The subsequent result that we present rests on the assumption that $\lim _{A \rightarrow 0} D_{A}^{\prime}>-\infty$, meaning that the impact of adaptation, when adaptation is very low, is limited (Moser and Ekstrom, 2010). This assumption is inspired by the fact that it is not enough to e.g. only replace one tile on the roof with a strong, storm-resistant one, but in order to have a safer house one needs to redo the whole roof. Or, similarly, in order to prevent flooding it is not simply sufficient to use one sandbag, but instead one has to surround one's house with a flood barrier that is high enough. Hence the idea is that adaptation should have a certain threshold good character, or at least be not infinitely productive at the lowest margin. We also confirm that this is a reasonable 
assumption in our numerical exercise. Though this assumption is not necessary for the central result, it facilities the subsequent reasoning.

We furthermore impose the following technical condition.

Assumption $3 W>-\frac{1-D(0,0)}{D_{M}^{\prime}(0,0)}$ and $W>-\frac{1-D(0,0)}{D_{A}^{\prime}(0,0)}$.

These two conditions in Assumption 3 imply that mitigation and adaptation are, at least to some extent, beneficial to curb the impact of climate change and not too expensive. In other words, we assume that there is a role for either mitigation or adaptation in climate policy.

Assume a benevolent policy maker maximizes the sum of these utility functions across the population. Knowing that everyone behaves the same this policy maker maximizes

$$
V=N U((1-D(N M, A))(W / N-A-M)) .
$$

Then it is clear that the maximum is achieved when

$$
\begin{aligned}
-D_{A}^{\prime}(N M, A)(W / N-A-M) & \leq 1-D(N M, A), \\
-D_{M}^{\prime}(N M, A)(W / N-A-M) & \leq \frac{1-D(N M, A)}{N},
\end{aligned}
$$

where (2) holds with equality if $A>0$, while (3) holds with equality when $M>0$. We summarize the first results in the following proposition.

Proposition 1 Under Assumptions 1 and 2 the maximization problem 
(1) yields

1. a corner solution in both adaptation $A=0$ and mitigation $M=0$

if

$$
\frac{W}{N}<-\frac{1-D(0,0)}{D_{A}^{\prime}(0,0)}
$$

and

$$
W<-\frac{1-D(0,0)}{D_{M}^{\prime}(0,0)} \text {. }
$$

2. a corner solution in adaptation $A=0$ alone if, for an optimum interior $M^{*}$,

$$
M^{*}>\frac{W}{N}+\frac{1-D\left(N M^{*}, 0\right)}{D_{A}^{\prime}\left(N M^{*}, 0\right)},
$$

and

$$
M^{*}=\frac{1}{N}\left(W+\frac{1-D\left(N M^{*}, 0\right)}{D_{M}^{\prime}\left(N M^{*}, 0\right)}\right)
$$

which jointly requires

$$
D_{M}^{\prime}(N M, 0) N<D_{A}^{\prime}(N M, 0)
$$

3. and a corner solution in mitigation $M=0$ alone if, for an optimum interior $A^{*}$,

$$
A^{*}>\frac{1}{N}\left(W+\frac{1-D\left(0, A^{*}\right)}{D_{M}^{\prime}\left(0, A^{*}\right)}\right),
$$

and

$$
A^{*}=\frac{W}{N}+\frac{1-D\left(0, A^{*}\right)}{D_{A}^{\prime}\left(0, A^{*}\right)}
$$


which jointly requires

$$
N D_{M}^{\prime}\left(0, A^{*}\right)>D_{A}^{\prime}\left(0, A^{*}\right)
$$

4. an interior solution in mitigation $M>0$ and adaptation $A>0$ if

$$
W / N-A^{*}-M^{*}=-\frac{1-D\left(N M^{*}, A^{*}\right)}{D_{A}^{\prime}\left(N M^{*}, A^{*}\right)}=-\frac{1-D\left(N M^{*}, A^{*}\right)}{N D_{M}^{\prime}\left(N M^{*}, A^{*}\right)},
$$

which requires

$$
N D_{M}^{\prime}\left(N M^{*}, A^{*}\right)=D_{A}^{\prime}\left(N M^{*}, A^{*}\right) .
$$

Proof 1 Follows directly from perturbing equations (2) and (3) and applying the Kuhn-Tucker conditions.

We now show that the public good character of mitigation and the private good character of adaptation play a crucial role for the optimal mix between adaptation and mitigation. In particular, we shall not, as is usual, focus on the demand side (properties of non-excludable and non-rival) of public goods, but instead on the supply side. As suggested above, the focus will be on the first-best, the social optimum, and thus we also do not look at the free-rider problem or the externalityinduced inefficiencies of over/under-provision which are generally associated with public goods. Instead, we look at the supply side in order 
to understand what makes a public good more 'public' relative to a private good.

Imagine you are a policy maker and you maximize wealth subject to adaptation and mitigation for the world as a whole $(N=1)$. In this case, the public good mitigation would be indistinguishable from a private good. In contrast, assume you maximize over the major regions of the world (e.g. RICE-2010 model assumes $N=12$ ). Then the fact that the world income is now split over 12 regions matters for the optimal choices. Take this now to the extreme and assume that 7.3 billion individuals are considered by the policy maker. Average income will be very low in this case, and consequently there will only be a limited budget available for private adaptation, while the potential sum for the public good mitigation can be very large. Intuitively, this should favour the provision of the public good mitigation over the private good adaptation.

Let us see whether this intuition applies to the optimal mix between the public good mitigation and the private good adaptation. Assume we are in case 2, which corresponds to parameter conditions that yield an interior solution in mitigation but a corner in adaptation. Then from the optimal condition for $M^{*}$, equation (7), we get

$$
\frac{d M^{*}}{d N}=-\frac{M^{*}}{N}=-\frac{1}{N^{2}}\left(W+\frac{1-D}{D_{M}^{\prime}}\right)<0
$$


The left-hand side of inequality (6) decreases in $N$. In contrast, the right-hand side of the inequality changes with $N$ according to

$$
\frac{d\left(\frac{W}{N}+\frac{1-D\left(N M^{*}, 0\right)}{D_{A}^{\prime}\left(N M^{*}, 0\right)}\right)}{d N}=-\frac{W}{N^{2}} .
$$

Hence, the left-hand side of the inequality reduces more slowly than the right-hand side if $N$ increases. As a result, if case 2 applies for a given $N$, then it will still hold for increasing $N$. This is also confirmed for the joint condition (8) which, if it holds for a given $N$, also holds for a larger $N$.

Assume now we are in case 3, thus $M=0$ and $A>0$ is optimal. Then from the optimal $A^{*}$ derived in equation (10) we obtain

$$
\frac{d A}{d N}=-\frac{W}{N^{2}\left(2+\frac{1-D(0, A)}{D_{A}^{\prime}(0, A)^{2} D_{A A}^{\prime \prime}}\right)}<0 .
$$

In addition, from equation (10) we can find that the optimal $A^{*}=0$ for $N \geq-\frac{D_{A}^{\prime}(0,0) W}{(1-D(0,0))}$.

We, therefore, find that for increasing $N$ it becomes increasingly unlikely that case 3 holds. The condition for this is summarized in the following proposition.

Proposition $2 A^{*}=0$ if, for any optimal $M, N \geq \frac{-D_{A}^{\prime}(N M, 0) W}{1-D(N M, 0)}$

Proof 2 Based on equation (10), we re-write the condition from Propo- 
sition 2 as

$$
\frac{W}{N}=A^{*}-\frac{1-D\left(0, A^{*}\right)}{D_{A}^{\prime}\left(0, A^{*}\right)} .
$$

As $A^{*}-\frac{1-D\left(0, A^{*}\right)}{D_{A}^{\prime}\left(0, A^{*}\right)}$ is an increasing function of $A$ and $-\frac{1-D(0,0)}{D_{A}^{\prime}(0,0)}>0$, then this condition will not be satisfied if $W / N<-\frac{1-D(0,0)}{D_{A}^{\prime}(0,0)}$. Also,

$$
\frac{d\left(\frac{1-D(0,0)}{D_{A}^{\prime}(0,0)}\right)}{d(N M)}=-\left(\frac{D_{A M}^{\prime \prime} W}{1-D}+\frac{D_{A}^{\prime} D_{M}^{\prime} W}{1-D)^{2}}\right)<0 .
$$

Re-writing yields the condition in the proposition above.

Figure 1 shows the condition under which the maximization problem yields a corner solution in adaptation and an interior solution in mitigation given that Assumption 3 holds.

Hence, for a sufficiently disaggregated welfare function we find that mitigation should be favoured over adaptation. Furthermore, we conjecture that this result will continue to hold in the case of multiple periods and asymmetric agents, and it will be strengthened if we include uncertainty, the risk of climate catastrophes, and e.g. the inability to migrate to safer regions. In addition, this complements the results of the Aggregation Dilemma (Schumacher, 2014), namely that a policy maker should evaluate climate policy preferably at smaller levels of aggregation since the averaging away of climate impacts at higher levels of aggregation implies an underestimation of the social cost of carbon. 
Figure 1: The corner solution for adaptation

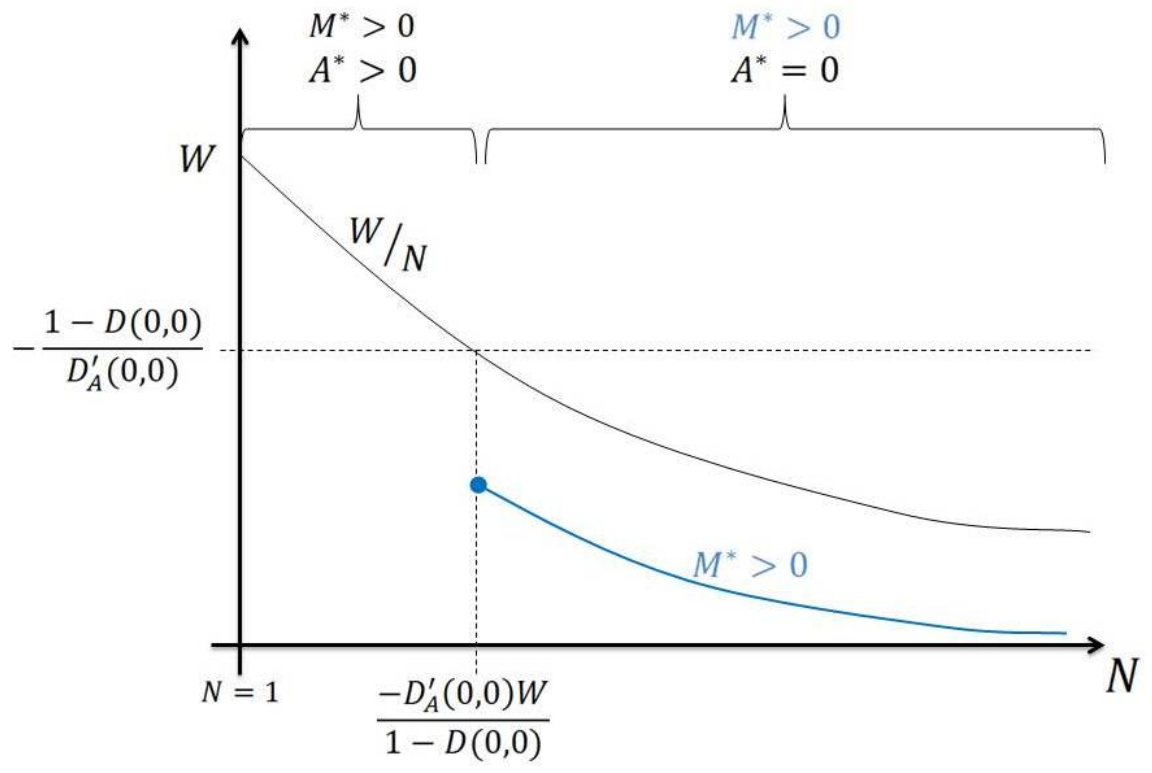

The result above also suggests that both representative agent models, such as Kane and Shogren (2000), Lecocq and Shalizi (2007), Yohe and Strzepek (2007), De Zeeuw and Zemel (2012), Bosello et al. (2013), Bréchet et al. (2013), Ingham et al. (2013), Tsur and Withagen (2013), van der Ploeg and de Zeeuw (2013), Zemel (2015), or integrated assessment models based on a global or regional split-up of the world, such as Hope (2006), De Bruin et al. (2009) or Bosello et al. (2010), will underestimate the optimal mitigation action and overestimate the optimal adaptation effort since they do not, or only minimally, take the public versus private good setting into account. 


\section{Empirical considerations}

We will now investigate inhowfar these theoretical results carry forward to empirically relevant settings. To do so we build upon Golosov et al. (2014) and define the damage function as follows.

Assumption 4 The damage function takes the form $D\left(\sum_{1}^{N} M_{i}, A_{i}\right)=$

$1-\exp \left(-\gamma\left(A_{i}\right)\left(S\left(W, \sum_{i} M_{i}\right)-\bar{S}\right)\right)$, where $\gamma\left(A_{i}\right)$ denotes the damage elasticity, while $S\left(W, \sum_{i} M_{i}\right)-\bar{S}$ is the difference between the current atmospheric carbon level and the pre-industrial one.

Hassler et al. (forthcoming) show that this damage function is a useful approximation relative to Nordhaus' (Nordhaus, 2007) damage function. Golosov et al. (2014) assume the damage elasticity parameter to be given exogenously, while we endogenize it through adaptation expenditure $\gamma\left(A_{i}\right)$.

An obvious question is as to how adaptation affects the damage elasticity parameter and how mitigation precisely affects carbon emissions. Clearly, there is an inherent lack of acceptable estimates concerning the way adaptation and mitigation help to reduce damages from climate change. Based on a survey in Tol et al. (1998), De Bruin et al. (2009) estimate that the costs of adaptation increase exponentially with the damages avoided. The functional form that we use henceforth and that approximates this is given in Assumption 5 below. 
Similarly, it is known that mitigation at low carbon emissions is reasonable cheap, while trying to mitigate all emissions is extremely costly. As mitigation may take many forms of emission reductions, such as investments in renewable energies like wind or solar, reforestation projects or investments in less carbon-intensive products, we take the empirical form given in Assumption 5.

Assumption 5 The damage elasticity is given by $\gamma\left(A_{i}\right)=\frac{\gamma}{1+A_{i}}$. The atmospheric carbon level is given by $S\left(W, \sum_{i} M_{i}\right)=\phi \frac{W}{1+\sum_{i} M_{i}}+848$.

Thus, both the damage elasticity and the atmospheric carbon level are convex functions of their arguments. We also take it that mitigation will not reduce the level of atmospheric carbon below the pre-industrial level, which is not a necessary but convenient assumption. In the definition of $S\left(W, \sum_{i} M_{i}\right)$ the value 848 is the current (2015) level of atmospheric carbon measured in Gigatons Carbon (GtC).

One may argue that higher levels of adaptation lead to lower net income levels and thus less carbon is emitted. However, there are many cases where adaptation actually increases emissions, e.g. via increased use of air conditioning in order to compensate for rising temperatures. Similarly, improving one's housing structure requires the production of more cement, of stronger tiles, of better isolated windows, all of which adds to carbon emissions. We thus take the most reasonable case and assume that producing a unit of adaptation expenditure has the same impact on the atmospheric carbon stock as a unit of income. 
In the following we will take this static model and assume that a benevolent policy maker looks ahead until 2050 when deciding upon the optimal adaptation and mitigation policy. Instead of adding utilities over the different periods we take average IPCC climate, as well as average World Bank population and income growth scenarios. We then sum up over the income from 2015 to 2050, and allow the policy maker to choose his climate policy statically. By doing so we will only obtain the average per period adaptation and mitigation expenditure, and ignore potential effects that are due to the curvature of the utility function or discounting. While this may somewhat affect the level of the optimal choices, this should not impact the qualitative results. Furthermore quantitative differences should be small for the low discount rates that are currently used in climate policy, and also for utility functions with little curvature (e.g. the DICE model of Nordhaus uses a logarithmic utility).

It is now required to calibrate the parameters $\gamma$ and $\phi$. The parameter $\gamma$ is the damage elasticity. We use the RCP8.5 scenario of the IPCC, which is an unmitigated scenario that predicts a level of atmospheric carbon of 1,378 GtC in 2050. According to Figure SPM.5 from the 2014 IPCC Synthesis Report (IPCC, 2014b), the associated warming will be around $2.5^{\circ} \mathrm{C}$. Damage estimates for this level of warming vary to some degree. According to the IPCC (Field et al., 2014) and the Stern review (Stern, 2007), losses from a $2^{\circ} \mathrm{C}$ temperature increase amount to between 0.2 to $2 \%$ of income, with losses being more likely 
at the higher end of the spectrum. Thus, a $2.5^{\circ} \mathrm{C}$ warming is likely to be closer to losses of $2 \%$, if not higher. In a recent study, Burke et al. (2015) estimate the aggregated world damages for $2.5^{\circ} \mathrm{C}$ warming to be $10 \%$ of world GDP. Due to a lack of better estimates we place slightly more weight on the estimates from the IPCC, and take it that a $2{ }^{\circ} \mathrm{C}$ warming induces damages of $4 \%$ of world GDP. The pre-industrial level of atmospheric carbon was around $590 \mathrm{GtC}$ (in 1750). Assuming that this level of carbon was such that mankind had fully adapted to the climate conditions, then using this information to estimate $\gamma$ we find that the unabated and unmitigated baseline scenario of 1,378 GtC in 2050 yields $0.96=1-\exp (-\gamma(1,378-590))$. Thus, this gives a value of $\gamma=5.18 \times 10^{-5}$. Golosov et al. (2014) obtain a very similar damage elasticity of $\gamma=5.3 \times 10^{-5}$. Furthermore, our damage estimates conform very closely to those by Nordhaus (2007), whose estimates would yield a damage of $3.5 \%$ at 1,378 GtC. However, our damage estimates are more linear in temperature than Nordhaus (2007) and overestimate the damages for low carbon concentrations but underestimate them for high levels of carbon concentrations. Nevertheless, a more linear relationship makes our model more in line with the recent empirical results of Burke et al. (2015).

The parameter $\phi$ is obtained as follows. The Gross World Product (in PPP, 2011 dollars) was 107.5 trillion US \$. Annual world carbon emissions are currently 10.35 GtC. Thus, the propensity to emit from world income is $\phi=10.35 / 107.5$. Since, according to the IPCC 
(2014a), roughly $50 \%$ of the emitted carbon leaves the atmosphere during the course of a couple of years, we multiply this by 0.8 , which takes into account that more carbon is emitted closer to 2050 implying that less could have left the atmosphere. We set the expected world growth rate until 2050 to $3 \%$, which is slightly lower than the recent $3.4 \%$ noted in the IMF's World Economic Outlook but includes the potential for growth convergence. Given that the pre-industrial carbon level was 590 GtC in 1790 and that the current level of carbon in the atmosphere is $848 \mathrm{GtC}$, then this yields ${ }^{2}$ a maximum carbon level of 1,372 GtC in 2050, which corresponds very closely to the $1,378 \mathrm{GtC}$ obtained via the RCP8.5 scenario of the IPCC. Thus, it seems this simple model approximates the more complicated integrated assessment models rather well.

We then numerically maximize the welfare function under different assumptions on how the policy maker aggregates the social welfare function: We assume (s)he may maximize the welfare function treating the world as a) a single entity (the world); b) split up in 12 regions (e.g. as in the RICE model); c) split up in its 193 countries; d) split up into 8 billion people ${ }^{3}$. The results are depicted in Table 1 . We observe that if the policy maker takes a country-level perspective, then the optimal adaptation expenditure tends to zero. In fact, given the calibration

\footnotetext{
${ }^{2}$ The calculation is as follows: $848 G t C+0.8 \times 10.35 G t C / 107.5 \$ \times \sum_{t=0}^{3} 5(1+$ $0.03)^{t} 107.5 \$=1,372 \mathrm{GtC}$.

${ }^{3}$ There are currently 7.3 billion people on this planet. According to the World Bank, the world population may (intermediate scenario) approach 8.6 billion by 2050. An average over the period 2015-2050 is roughly 8 billion.
} 
Table 1: Numerical results

\begin{tabular}{lccc}
\hline Split-up & Adaptation & Mitigation & Total mitigation \\
\hline World & 10.71 & 2.967 & 2.967 \\
RICE regions (12) & 2.085 & 0.56 & 6.715 \\
Countries (193) & 0 & 0.065 & 12.484 \\
Individuals (8 bill.) & 0 & $1.56 \times 10^{-9}$ & 12.484 \\
\hline
\end{tabular}

above, adaptation will be equal to zero for a social welfare function that consists of a disaggregation level of 110 or more agents/regions. The results presented here confirm that it is important to fully take the public good nature of mitigation into account when deciding upon the optimal mix with the private good adaptation.

\subsection{What is the 'right' $N$ to consider?}

It is not entirely clear as to what is the 'right' level at which the welfare function should be evaluated. The important question, therefore, is at which level decisions are taken. Clearly, aggregation helps us to simplify exposition and it also aids us in the understanding of results, it helps us in the modelling and very often it is easier to predict the evolution of the whole than the evolution of its parts. Furthermore, data availability at the individual level is scarce and incomplete. Consequently, higher levels of aggregation tend to be preferred, which also explains the lack of country-level integrated assessment models. However, ever since COP20, and especially in the light of COP21, a global unified regulatory scheme seems far from achievable, and $\mathrm{Na}$ - 
tionally Appropriate Mitigation Actions re-introduce the country-level perspective back into climate policy making. This thus implies that a policy maker should set $N$ at the country-level.

At the same time, most adaptation efforts are undertaken at the household (e.g. house protection against storms) or city (e.g. dam construction) level. For example, farmers protect their soils from desertification by building appropriate water reservoirs. Families invest heavily into fortifying their houses against storm damage. Migrants pay large sums of money to migrate to places that are less susceptible to climate change. These actions tend to see very little governmental support but they nevertheless make the brunt of adaptation efforts. Clearly, this is also unlikely to change in the future. As a result, a policy maker should optimally choose adaptation efforts at the household level. This thus implies that $N$ should be considered to be sufficiently large for the result above to hold for most functional forms of damages.

What one should take away is that optimal climate policy should thus be at least taken with the country-level perspective in mind. In this case the numerical results have shown that adaptation should be set equal to zero and mitigation should be set at a positive level. Again, this is a direct implication of the fact that, while adaptation is a private good, mitigation is a public good and thus small contributions of everyone can have significant impacts at the large. If everyone were to act unilaterally and spend money on individual adaptation then a 
policy maker would evaluate this as a loss of welfare.

\section{Conclusion}

If we take the view of a benevolent world policy maker, then the result presented above suggests that, considering a sufficiently disaggregated welfare function (e.g. at the country level), the optimal adaptation effort will be zero, while mitigation effort should be positive. Conclusively, from a global perspective, the public good character of mitigation, by and large, indeed should favour mitigation action over the private good adaptation. From a global perspective, private adaptation thus represents a significant loss of welfare.

Based on a numerical exercise calibrated to real-world data we show that a policy maker who evaluates social welfare at the country-level (or higher levels of disaggregation) would not invest in adaptation, but instead would fully focus on mitigation. Furthermore, if adaptation is similar to a threshold good (i.e. take the case of a dam), then this strengthens the point raised in this article. Additional factors that strengthen the above result include uncertainty, the risk of climate catastrophes, the inability to migrate to safer regions, or the inability of the agricultural sector to adapt to certain climatic changes. The results presented here complement those from the Aggregation Dilemma (Schumacher, 2014), which states that the social cost of carbon increases the more disaggregated the welfare function is since aggregation 
averages (important) differences away.

Of course we all know that the world is not ruled by a benevolent planner. Does this imply this result has no meaning? Certainly not, since it simply states that, if we want to achieve the absolute optimum, then we should focus our maximum efforts on mitigation. It is thus a negative result on the position that adaptation necessarily has to play a role in our climate policy mix. Instead, it means that if our world leaders are unable to cooperate to a sufficient degree and we cannot achieve the best outcome for everyone, only then may adaptation play a role.

Thus, the point raised here suggests that policy makers should get their priorities straight: It is simply not true that "[e]ffective climate policy aimed at reducing the risks of climate change to natural and human systems involves a portfolio of diverse adaptation and mitigation actions." (Parry, 2007) Instead, considering the result presented here, the IPCC should write that "[e]ffective climate policy aimed at reducing the risks of climate change to natural and human systems must primarily consist of mitigation actions." 


\section{References}

Agrawala, Shardul, Francesco Bosello, Carlo Carraro, Enrica De Cian, Elisa Lanzi et al., "Adapting to climate change: costs, benefits, and modelling approaches," International Review of Environmental and Resource Economics, 2011, 5 (3), 245-284.

Bosello, Francesco, Carlo Carraro, and Enrica De Cian, "Climate policy and the optimal balance between mitigation, adaptation and unavoided damage," Climate Change Economics, 2010, 1 (02), $71-92$.

${ }_{-},{ }_{-}$, and ${ }_{-}$, "Adaptation can help mitigation: an integrated approach to post-2012 climate policy," Environment and Development Economics, 2013, 18 (03), 270-290.

Bréchet, Thierry, Natali Hritonenko, and Yuri Yatsenko, "Adaptation and mitigation in long-term climate policy," Environmental and Resource Economics, 2013, 55 (2), 217-243.

Brechet, Thierry, Natali Hritonenko, Yuri Yatsenko et al., "Domestic environmental policy and international cooperation for global commons," Technical Report, Université catholique de Louvain, Center for Operations Research and Econometrics (CORE) 2014 . 
Bruin, Kelly C De, Rob B Dellink, and Richard SJ Tol, "ADDICE: an implementation of adaptation in the DICE model," Climatic Change, 2009, 95 (1-2), 63-81.

Buob, Seraina and Gunter Stephan, "To mitigate or to adapt: How to confront global climate change," European Journal of Political Economy, 2011, 27 (1), 1-16.

Burke, Marshall, Solomon M Hsiang, and Edward Miguel, "Global non-linear effect of temperature on economic production," Nature, 2015.

Ebert, Udo and Heinz Welsch, "Adaptation and mitigation in global pollution problems: economic impacts of productivity, sensitivity, and adaptive capacity," Environmental and Resource Economics, 2012, 52 (1), 49-64.

Farnham, Martin and Peter Kennedy, "Adapting to Climate Change: Equilibrium Welfare Implications for Large and Small Economies," Environmental and Resource Economics, 2014, pp. 119.

Field, C.B., V.R. Barros, D.J. Dokken, K.J. Mach, M.D. Mastrandrea, T.E. Bilir, M. Chatterjee, K.L. Ebi, Y.O. Estrada, R.C. Genova, B. Girma, E.S. Kissel, A.N. Levy, S. MacCracken, P.R. Mastrandrea, and L.L. White (eds.), Summary for policymakers. In: Climate Change 2014: Impacts, Adaptation, 
and Vulnerability. Part A: Global and Sectoral Aspects. Contribution of Working Group II to the Fifth Assessment Report of the Intergovernmental Panel on Climate Change, Cambridge University Press, Cambridge, United Kingdom and New York, NY, USA, 2014.

Golosov, Mikhail, John Hassler, Per Krusell, and Aleh Tsyvinski, "Optimal taxes on fossil fuel in general equilibrium," Econometrica, 2014, 82 (1), 41-88.

Hassler, John, Per Krusell, and Jonas Nycander, "Climate policy," Economic Policy, forthcoming.

Hope, Chris, "The marginal impact of CO2 from PAGE2002: An integrated assessment model incorporating the IPCC $\backslash$ 's five reasons for concern," Integrated Assessment Journal, 2006, 6 (1), 19-56.

Ingham, Alan, Jie Ma, and Alistair M Ulph, "Can adaptation and mitigation be complements?," Climatic change, 2013, 120 (1-2), 39-53.

IPCC, Climate change 2013: The physical science basis, [Core writing team, Stocker, Thomas and Qin, Dahe and Plattner, GianKasper and Tignor, $M$ and Allen, Simon $K$ and Boschung, Judith and Nauels, Alexander and Xia, Yu and Bex, Vincent and Midgley, Pauline $M$ (eds.)], Cambridge University Press Cambridge, UK, and New York, 2014. 
_, Climate Change 2014: Synthesis Report. Contribution of Working Groups I, II and III to the Fifth Assessment Report of the Intergovernmental Panel on Climate Change [Core Writing Team, R.K. Pachauri and L.A. Meyer (eds.)], IPCC, Geneva, Switzerland, 2014.

Kane, Sally and Jason F Shogren, "Linking adaptation and mitigation in climate change policy," Climatic Change, 2000, 45 (1), $75-102$.

Konrad, Kai A and Marcel Thum, "The role of economic policy in climate change adaptation," CESifo Economic Studies, 2013, p. ift003.

Lecocq, Franck and Zmarak Shalizi, "Balancing expenditures on mitigation of and adaptation to climate change: an exploration of issues relevant to developing countries," World Bank Policy Research Working Paper, 2007, (4299).

Mendelsohn, Robert, "Efficient adaptation to climate change," Climatic Change, 2000, 45 (3-4), 583-600.

Moser, Susanne C and Julia A Ekstrom, "A framework to diagnose barriers to climate change adaptation," Proceedings of the National Academy of Sciences, 2010, 107 (51), 22026-22031.

Neumayer, Eric, Weak versus strong sustainability: exploring the limits of two opposing paradigms, Edward Elgar Publishing, 2003. 
Nordhaus, William D, "To tax or not to tax: Alternative approaches to slowing global warming," Review of Environmental Economics and policy, 2007, 1 (1), 26-44.

Parry, Martin L, Climate Change 200\%: impacts, adaptation and vulnerability: contribution of Working Group II to the fourth assessment report of the Intergovernmental Panel on Climate Change, Vol. 4, Cambridge University Press, 2007.

Patt, Anthony G, Detlef P van Vuuren, Frans Berkhout, Asbjørn Aaheim, Andries F Hof, Morna Isaac, and Reinhard Mechler, "Adaptation in integrated assessment modeling: where do we stand?," Climatic Change, 2010, 99 (3-4), 383-402.

Schumacher, Ingmar, "The Aggregation Dilemma," Technical Report, Department of Research, Ipag Business School 2014.

Sen, Amartya Kumar, Commodities and Capabilities: Professor Dr. P. Hennipman Lectures in Economics, 1982 Delivered at the University of Amsterdam, Oxford University Press, 1987.

Stern, Nicholas, The economics of climate change: the Stern review, Cambridge University Press, 2007.

Tol, Richard SJ, Samuel Fankhauser, and Joel B Smith, "The scope for adaptation to climate change: what can we learn from the impact literature?," Global Environmental Change, 1998, 8 (2), 109-123. 
Tsur, Yacov and Cees Withagen, "Preparing for catastrophic climate change," Journal of Economics, 2013, 110 (3), 225-239.

van der Ploeg, Frederick and Aart de Zeeuw, "Climate policy and catastrophic change: be prepared and avert risk," Technical Report, European University at St. Petersburg, Department of Economics 2013.

Yohe, Gary and Kenneth Strzepek, "Adaptation and mitigation as complementary tools for reducing the risk of climate impacts," Mitigation and Adaptation Strategies for Global Change, 2007, 12 (5), 727-739.

Zeeuw, Aart De and Amos Zemel, "Regime shifts and uncertainty in pollution control," Journal of Economic Dynamics and Control, 2012, 36 (7), 939-950.

Zemel, Amos, "Adaptation, mitigation and risk: An analytic approach," Journal of Economic Dynamics and Control, 2015, 51, 133147. 